\title{
DELETION DETECTION FOR DIAGNOSIS OF DUCHENNE MUSCULAR DYSTROPHY IN THE JAPANESE POPULATION-COMPARISOM BETWEEN THE POLYMERASE CHAIN REACTION AND THE SOUTHERN BLOT ANALYSIS-
}

\author{
Susumu Katayama, Naoki Takeshita, Tomone Yano, \\ Tsuneyuki UbagaI, Xiao Jin QIU, Yukiko KatagirI, \\ Harumi Kubo, and Shun HIRakawa
}

The First Department of Obstetrics and Gynecology, School of Medicine, Toho University, Ohmorinishi, Ohta-ku, Tokyo 143, Japan

\begin{abstract}
Summary We compared the efficacy of the multiplex PCR with that of the cDNA analysis for detection of deletions of the DMD gene in the Japanese patients. Thirty males with DMD from 27 Japanese families were studied by the multiplex PCR, and 24 of them were also investigated by Southern blot analysis. We used five dystrophin cDNA probes for deletion analysis. A total of 19 regions were amplified by the PCR to detect deletions, 9 regions by the method of Chamberlain et al. and another 10 regions by the method of Beggs et al. Deletions were detected in 14 $(52 \%)$ out of 27 DMD families by the PCR. Southern blot analysis detected deletions in $14(64 \%)$ out of 22 families. Thirteen $(93 \%)$ of the 14 DMD families with deletions detected by Southern blotting were also confirmed by the multiplex PCR. Provided care is taken in cases where the deletion is limited to a single exon, the multiplex PCR appears to be an efficient and useful alternative to conventional Southern blot analysis for detecting deletions during the prenatal and postnatal diagnosis of DMD.
\end{abstract}

Key Words Duchenne muscular dystrophy, deletion detection, cDNA probe, multiplex PCR

\section{INTRODUCTION}

Duchenne muscular dystrophy (DMD) is the most devastating human X-linked recessive disease with an incidence of about one in 4,000 male live births (Moser, 1984). The number of patients with DMD is estimated to be about 7,000, and every year 150 new patients are born in Japan. A boy affected with DMD generally

Received December 22, 1992; Revised Accepted March 8, 1993. 
develops symptoms before the age of 6 years, is confined to a wheelchair by age 12 , and dies by age 20 . Since DMD is a fatal disease with no known cure, determining whether or not an at-risk fetus is affected is very important for women considering childbirth who have DMD in their families. The diagnosis of carrier status and the prenatal diagnosis of DMD are both significant issues with respect to genetic counseling.

Rapid progress in the field of DNA diagnosis of DMD has been made recently. Restriction fragment length polymorphism (RFLP) analysis with genomic DNA probes (Monaco AP et al., 1985) and deletion detection analysis with cDNA probes (Koenig et al., 1987) have been developed utilizing the Southern blotting method. In addition, the multiplex polymerase chain reaction (PCR) has become available, which is a technique for amplifying multiple exons within a gene to detect deletions (Chamberlain et al., 1988), while PCR-RFLP analysis can be used to look for DNA polymorphisms within a gene by digesting the PCR products with appropriate restrcition enzymes (Roberts et $a l ., 1989$ ). PCR analysis usually enables results to be obtained within 1-2 days by a relatively simple procedure and is now emerging as an alternative to Southern blot analysis, which is a laborious procedure, requires the handling of radioactive materials, and usually takes $1-2$ weeks to provide a results. Deletion detection with PCR analysis is especially useful in diagnosing DMD and in antenatal diagnosis. Several separate studies on the efficacy of Southern blot analysis with CDNA probes and PCR analysis are available for detecting deletions in the Japanese population (Sugino et al., 1989; Asano et al., 1991; Kitoh et al., 1992).

This study compared the efficacy of multiplex PCR with that of the Southern blot analysis with cDNA probes for the detection of DMD deletions because these two analytical methods have not been compared enough previously in the Japanese population.

\section{MATERIALS AND METHODS}

Thirty males with DMD from 27 Japanese families were studied by the multiplex PCR to detect deletions. Twenty-two of these DMD families were also investigated by Southern blot analysis and the detection of deletions was compared. Fourteen of the families had only one sporadic male with DMD in their pedigree, while the other 13 families had at least two males affected with DMD. DNA was extracted from peripheral white blood cells by the standard method.

Southern blot analysis was done as follows. DNA $(7 \mu \mathrm{g})$ was digested for $12 \mathrm{hr}$ with 5 units/ $\mu \mathrm{g}$ DNA of the appropriate restriction endonuclease according to the manufacturer's recommendations. The digests were then subjected to electrophoresis overnight on $1 \%$ agarose gels, and the DNA was transferred from the gel to nylon filters (Hybond $\mathrm{N}+$; Amersham, U.K.) using a vacuum transfer system (Pharmacia LKB, Sweden) and $0.4 \mathrm{~N} \mathrm{NaOH}$ transfer buffer. The filters were then 
hybridized using cDNA probes labeled by nick translation and with $\left[\alpha^{-32} \mathrm{P}\right] \mathrm{dCTP}$ (Amersham, U.K.). They were washed in $2 \times$ SSC and $1 \times$ Denhardt's solution at room temperature for $45 \mathrm{~min}$, then in $0.1 \times \mathrm{SSC}$ and $0.1 \%$ sodium dodecyl sulfate (SDS) gentle shaking at $52^{\circ} \mathrm{C}$ for $90 \mathrm{~min}$, and finally four times in $0.1 \times \mathrm{SSC}$. Filters were then exposed to Kodak X-OMAT AR films between intensifying screens at $-80^{\circ} \mathrm{C}$ overnight and developed. We used five dystrophin cDNA probes

Table 1. Oligonucleotide sequences of the primers used in the multiplex PCR analysis.

\begin{tabular}{|c|c|c|c|}
\hline \multicolumn{2}{|c|}{ Chamberlain's primers } & & \multirow[b]{2}{*}{ Sequence } \\
\hline Exon & Size(bp) & & \\
\hline 4 & 196 & & $\begin{array}{l}\text { TTG TCG GTC TCC TGC TGG TCA GTG } \\
\text { CAA AGC CCT CAC TCA AAC ATG AAG C }\end{array}$ \\
\hline 8 & 360 & $\mathrm{~F}$ & GTC CTT TAC ACA CTY TAC CTG TTG AG \\
\hline & & $\begin{array}{l}R \\
F\end{array}$ & GGC CTC ATT CTC ATG TTC TAA TTA G \\
\hline 12 & 331 & $\begin{array}{l}F \\
R\end{array}$ & $\begin{array}{l}\text { GAT AGT GGG CTT TAC TTA CAT CCT TC } \\
\text { GAA AGC AGG CAA CAT AAG ATA CAC CT }\end{array}$ \\
\hline 17 & 416 & $\begin{array}{l}F \\
R\end{array}$ & $\begin{array}{l}\text { GAC TTT CGA TGT TGA GAT TAC TTT CCC } \\
\text { AAG CTT GAG ATG CTC TCA CCT TTT CC }\end{array}$ \\
\hline 19 & 459 & $\begin{array}{l}\mathrm{F} \\
\mathrm{R}\end{array}$ & $\begin{array}{l}\text { TTC TAC CAC ATC CCA TTT TCT TCC A } \\
\text { GAT GGC AAA AGT GTT GAG AAA AAG TC }\end{array}$ \\
\hline 44 & 268 & $\begin{array}{l}\mathrm{F} \\
\mathrm{R}\end{array}$ & $\begin{array}{l}\text { CTT GAT CCA TAT GCT TIT ACC TGC A } \\
\text { TCC ATC ACC CTT CAG AAC CTG ATC T }\end{array}$ \\
\hline 45 & 547 & $\begin{array}{l}F \\
R\end{array}$ & $\begin{array}{l}\text { AAA CAT GGA ACA TCC TTG TGG GGA C } \\
\text { CAT TCC TAT TAG ATC TGT CGC CCT AC }\end{array}$ \\
\hline 48 & 506 & $\begin{array}{l}\mathrm{F} \\
\mathrm{R}\end{array}$ & $\begin{array}{l}\text { TTG AAT ACA TTG GTT AAA TCC CAA CAT G } \\
\text { CCT GAA TAA AGT CTT CCT TAC CAC AC }\end{array}$ \\
\hline 51 & 388 & $\begin{array}{l}F \\
R\end{array}$ & $\begin{array}{l}\text { GAA ATT GGC TCT TTA GCT TGT GTT TC } \\
\text { GGA GAG TAA AGT GAT TGG TGG AAA ATC }\end{array}$ \\
\hline \multicolumn{4}{|c|}{ Beggs'primers } \\
\hline Exon & Size (bo) & & Sequence \\
\hline $\mathrm{Pm}$ & 528 & $F$ & TAG ACA GTG GAT ACA TAA CAA ATG CAT G \\
\hline 3 & 4.10 & $\mathrm{~F}$ & $\begin{array}{l}\text { TTC TCC GAA GGT AAT TGC CTC CCA GAT CTG AGT CC } \\
\text { TCA TCC ATC ATC TTC GGC AGA TTA A }\end{array}$ \\
\hline & & $\mathrm{R}$ & CAG GCG GTA GAG TAT GCC AAA TGA AAA TCA \\
\hline 6 & 202 & $\begin{array}{l}F \\
R\end{array}$ & $\begin{array}{l}\text { CCA CAT GTA GGT CAA AAA TGT AAT GAA } \\
\text { GTC TCA GTA ATC TTC TTA CCT ATG ACT ATG G }\end{array}$ \\
\hline 13 & 238 & $\mathrm{~F}$ & AAT AGG AGT ACC TGA GAT GTA GCA GAA AT \\
\hline 43 & 357 & $\begin{array}{l}R \\
F \\
B\end{array}$ & $\begin{array}{l}\text { CTG ACC TTA AGT TGT TCT TCC AAA GCA G } \\
\text { GAA CAT GTC AAA GTC ACT GGA CTT CAT CG }\end{array}$ \\
\hline 47 & 181 & $\begin{array}{l}\mathrm{R} \\
\mathrm{F}\end{array}$ & $\begin{array}{l}\text { ATA TAT GTG TTA CCT ACC CTT GTC GGT CC } \\
\text { CGT TGT TGC ATT TGT CTG TTT CAG TTA C }\end{array}$ \\
\hline & & $\mathrm{R}$ & GTC TAA CCT TTA TCC ACT GGA GAT TIG \\
\hline 49 & 439 & $\mathrm{~F}$ & GTG CCC TTA TGT ACC AGG CAG AAA TTG \\
\hline 50 & 271 & $\begin{array}{l}R \\
F \\
R\end{array}$ & $\begin{array}{l}\text { GCA ATG ACT CGT TAA TAG CCT TAA GAT C } \\
\text { CAC CAA ATG GAT TAA GAT GTT CAT GAA T } \\
\text { TCT CTC TCA CCC AGT CAT CAC TTC ATA G }\end{array}$ \\
\hline 52 & 113 & F & AAT GCA GGA ITT GGA ACA GAG GCG TCC \\
\hline 60 & 139 & $\begin{array}{l}R \\
F \\
R\end{array}$ & $\begin{array}{l}\text { TTC GAT CCG TAA TGA TTG TTC TAG CCT C } \\
\text { AGG AGA AAT TGC GCC TCT GAA AGA GAA CG } \\
\text { CTG CAG AAG CTT CCA TCT GGT GIT CAG }\end{array}$ \\
\hline
\end{tabular}

$\mathrm{Pm}$, muscle-specific promotor plus a quarter of exon $1 ; \mathrm{F}$, forward; $\mathrm{R}$, reverse. 
for the detection of deletions $(1-2 a, 2 b-3,4-5 a, 5 b-7$, and 8 from the 5 ' end of the DMD gene-all obtained from the American Type Culture Collection).

The multiplex PCR was performed as follows. A total of 19 regions were amplified to detect deletions, 9 regions (exons 4, 8, 12, 17, 19, 44, 45, 48, and 51) by the method of Chamberlain et al. (1988) and the other 10 regions (muscle-specific promoter, and exons 3, 6, 13, 43, 47, 49, 50, 52, and 60) by the method of Beggs et al. (1990). Primers were purchased from a commercial laboratory (Sawady Technology, Tokyo). Oligonucleotide sequences of the primers used in the multiplex PCR are shown in Table 1. One hundred microliters of the total reaction mixture (250 $\mathrm{ng}$ of template DNA, $1.5 \mathrm{~mm}$ dNTPs (dATP, dCTP, dGTP, and dTTP), $10 \times$ reaction buffer, $15 \mu \mathrm{mol}$ of each primer, and 2.5 units of Taq polymerase) was amplified for 23 cycles after $6 \mathrm{~min}$ of initial denaturation at $94^{\circ} \mathrm{C}$. Each cycle consisted of $30 \mathrm{sec}$ of denaturation at $94^{\circ} \mathrm{C}, 30 \mathrm{sec}$ of annealing at $60^{\circ} \mathrm{C}$, and $4 \mathrm{~min}$ of elongation at $72^{\circ} \mathrm{C}$. These 23 cycles were followed by a final $7 \mathrm{~min}$ of elongation at $65^{\circ} \mathrm{C}$. Amplified products were subjected to electrophoresis on two separate $6 \%$ polyacrylamide gels $(14 \mathrm{~mA}, 45 \mathrm{~min})$, stained with ethidium bromide, and photographed with a Polaroid camera for analysis.

\section{RESULTS}

Deletions were detected in $14(52 \%)$ out of 27 DMD families when a total of 19 regions were amplified by the PCR. Southern blot analysis detected deletions in $14(64 \%)$ out of 22 DMD families using the five cDNA probes (Table 2 ). Thirteen families $(93 \%)$ of the 14 DMD families with deletions detected by cDNA probes were also confirmed with the multiplex PCR. The presence of deletions in the remaining one DMD family ( $7 \%$ ) whose deletions were detected by cDNA probes could not be confirmed with the multiplex PCR (Table 3).

Figure 1 shows the extent and location of the deletions detected by the five cDNA probes in relation to the 19 exons amplified in the PCR. Two brothers with DMD (patients No. 1 and 1' had deletions in exon 3 detected by cDNA probe 1-2a which could not be confirmed using the multiplex PCR. In patient No. 8, the deletion extended from exon 45 to 49 on PCR analysis while it was from exon 45 to 48 on cDNA analysis. Among the 13 families with 15 deletions confirmed by the multiplex PCR, three families $(23 \%)$ were detected by Chamberlain's method

Table 2. Detection of deletions by the multiplex PCR and the Southern blot analysis using cDNA probes.

\begin{tabular}{lccc}
\hline Method & $\begin{array}{c}\text { Number of DMD } \\
\text { families examined }\end{array}$ & $\begin{array}{c}\text { Number of DMD } \\
\text { families with deletions }\end{array}$ & $\begin{array}{c}\text { Detection } \\
\text { rate }(\%)\end{array}$ \\
\hline Multiplex PCR & 27 & 14 & 52 \\
Southern blotting & 22 & 14 & 64 \\
\hline
\end{tabular}


Table 3. Correspondence of deletion detection between the multiplex PCR and the Southern blot analysis.

\begin{tabular}{lccc}
\hline Method & $\begin{array}{c}\text { Number of DMD } \\
\text { families examined }\end{array}$ & $\begin{array}{c}\text { Number of DMD } \\
\text { families with deletion }\end{array}$ & $\begin{array}{c}\text { Correspondence } \\
\text { rate }(\%)\end{array}$ \\
\hline Southern blotting & 22 & 14 & \\
Multiplex PCR & 14 & 13 & 93 \\
\hline
\end{tabular}

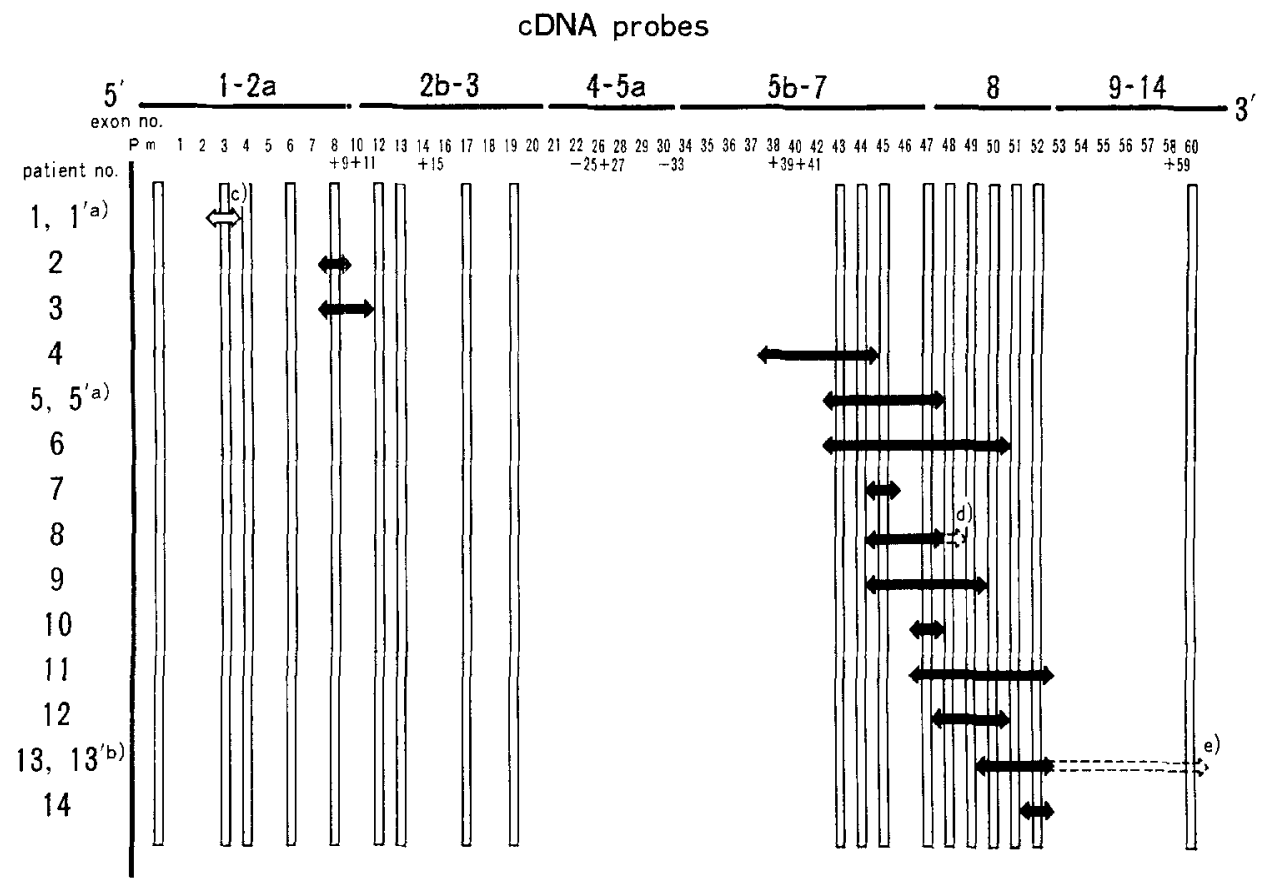

Fig. 1. Extent and location of the deletions detected by the five cDNA probes in relation to the 19 exons amplified in the PCR. a) Two brothers. b) Two cousins. c) Deletions detected with cDNA probes could not be confirmed by the multiplex PCR. d) The deletion extended from exon 45 to 49 on the PCR, while it extended from exon 45 to 48 on cDNA analysis. e) A junctional fragment was detected between exons 45 and 53 by cDNA probe 8 , but exon 50 was amplified by the PCR.

only, five ( $38 \%$ ) by the Begg's method only (1990), and five (38\%) by both methods. Thus, Chamberlain's method (1988) detected eight $(62 \%)$ of the 13 families with deletions, and the detection rate was increased considerably by adding Beggs' method.

\section{DISCUSSION}

We compared the efficacy between the multiplex PCR and the Southern blot analysis with cDNA probes for the detection of deletions in Japanese DMD pa- 
tients. The detection rate for Southern blotting was $64 \%$ with a total of five cDNA probes. This rate was higher than that in a previous study on Japanese patients which detected $25 \%$ of deletions in DMD $(5 / 20)$ and $50 \%$ of deletions in BMD $(9 / 18)$ (Asano et al., 1991), and was similar to the high rate found in Caucasians (Koenig et al., 1987). Deletions were concentrated at two hot spots where $73 \%$ of all deletions (11/15 deletions) were detected by two cDNA probes (1-2a and 8). Therefore, these two probes are efficient to screen for deletions. However, Southern blot analysis using cDNA probes has several disadvantages, since it requires the handling of radioactive materials, is a complex procedure, and takes a long time to obtain results. The multiplex PCR detected deletions in $52 \%$ of DMD patients when 19 exons were examined. This result was slightly lower than the $65 \%$ reported by Sannomiya (1991) and somewhat higher than the $38 \%$ reported by Minami (1991) in Japanese subjects using same 19 exons.

Of the deletions detected with cDNA probes, $93 \%$ could be confirmed by the multiplex PCR. However in two brothers (patients No. 1 and 1') deletions detected with cDNA probe 1-2a could not be confirmed by the PCR. Two possible explanations for this can be considered. One is that there was a failure to detect signals on the blot due to problems with Southern hybridization. The other explanation is that it was due to contamination of the test sample by undeleted DNA. In patient No. 8, the deletion was detected between exons 45 and 47 with cDNA probes and was extended to exon 48 by the multiplex PCR. Exon 48 is shown as a combination of 3.8 and $1.25 \mathrm{~kb}$ fragments with the cDNA probe, and it is sometimes difficult to determine precisely on Southern blots that only the 3.8 $\mathrm{kb}$ fragment of exon 48 is deleted because the $3.7 \mathrm{~kb}$ fragment for exon 50 is located just below it. In addition, the $1.25 \mathrm{~kb}$ fragment is also sometimes difficult to detect. PCR analysis has the problem of falsely identifying deletions where none exist because amplification can be prevented by the template DNA sequence polymorphism at the PCR primer annealing site (Abbs et al., 1991; Fujimura et al., 1990). Therefore, the true reason for this discrepancy is unclear. In the patients with a junctional fragment detected by cDNA probe 8 (patients No. 13 and 13', two cousins), the deletions was between exons 45 and 53, but exon 50 was amplified in the PCR. This difference may have been due to the partial conservation of a PCR primer annealing site on the template DNA.

Comparative studies of the detection of deletions by the multiplex PCR and cDNA analysis have not accumulated enough previously in Japanese DMD patients. In Caucasians, $82 \%$ of the deletions detected with cDNA probes were confirmed by multiplex PCR amplifying a total of 9 exons (Multicenter Study Group, 1992). This rate was increased to $98 \%$ when the number of regions amplified was expanded to 19 exons (Beggs et al., 1990). Fujishita et al. (1991) reported that $26(92 \%)$ of 28 deletions observed with Southern analysis were detected by PCR using only seven primer sets. Our study also showed a high detection rate that was almost consistent with these results. However, the results of PCR analysis sometimes 
differed from those of Southern blot analysis with cDNA probes. Although deletions covering several exons are reliably detected, reconfirmation is required by using different sets of primers for the same exons or analysis with cDNA probes in cases where deletion is limited to a single exon. This is particularly true in prenatal diagnosis.

In conclusion, provided these precautions are followed, multiplex PCR analysis appears to be an efficient, and useful alternative to conventional Southern blot analysis for detecting deletions when undertaking the prenatal or postnatal diagnosis of DMD.

Acknowledgments This work was supported in part by The Research Grant (2A-3) for Nervous and Mental Disorders from the Ministry of Health and Welfare, Japan.

\section{REFERENCES}

Abbs S, Yau SC, Clark S, Mathew CG, Bobrow M (1991): A convenient multiplex PCR system for the detection of dystrophin deletion: A comparative analysis with cDNA hybridization reveals mistypings by both methods. J Med Genet 28: 304-311

Asano J, Tomatsu S, Sukegawa K, Ikedo Y, Minami R, Iida M, Nishimura M, Nakagawa M, Ohsiro M, Orii T (1991): Gene deletions in the Japanese patients with Duchenne and Becker muscular dystrophies: Deletion study and carrier detection. Clin Genet 39: 419-424

Beggs A, Koenig H, Boyce FM, Kunkel LM (1990): Detection of $98 \%$ of DMD/BMD gene deletions by polymerase chain reaction. Hum Genet 86:45-48

Chamberlain JS, Gibbs RA, Ranier JF, Nguyen PN, Caskey CT (1988): Deletion screening of the Duchenne muscular dystrophy via multiplex DNA apmlification. Nucleic Acids Res 16: 11141

Fujimura FK, Northrup H, Beaudet AL, O'Brien WE (1990): Genotyping errors with the polymerase chain reaction. N Engl J Med 322: 61

Fujishita S, Shibuya N, Niikawa N, Nagataki S (1991): Gene-deletion and carrier detections, and prenatal diagnosis of Duchenne muscular dystrophy by analysis of the dystrophin gene amplified by polymerase chain reaction. Jpn J Human Genet 36: 317-324

Kitoh Y, Matsuo M, Nishio H, Takumi T, Nakajima T, Masumura T, Koga J, Nakamura H (1992): Amplification of the deletion rich exons of the dystrophin gene by polymerase chain reaction shows deletions in 36 of 90 Japanese families with Duchenne muscular dystrophy. Am J Med Genet 42: 453-457

Koenig M, Hoffman EP, Bertelson CJ, Monaco AP, Feener C, Kunkel LM (1987): Complete cloning of the Duchenne muscular dystrophy (DMD) cDNA and gene in normal and affected individuals. Cell 50: $509-517$

Minami R (1991): Heterogeneity of gene deletions and clinical manifestations among DMD patients in Hokkaido. Annual report of research on the genetic, epidermiologic, clinical, and therapeutic aspects of muscular dystrophy supported by the National Center for Neurology and Psychiatry (NCNP) of the Ministry of Health and Welfare, Japan. 9-12.

Monaco AP, Bertelson CJ, Middlesworth W, Colletti CA, Aldridge J, Fishbeck KH, Bartlett R, Pericak-Vance MA, Roses AD, Kurkel LM (1985): Detection of deletions spanning the Duchenne muscular dystrophy locus using a tightly linked DNA segment. Nature 316; 842-845

Moser H (1984): Duchenne muscular dystrophy: Pathogenic aspects and genetic prevention. Hum Genet 66: 17-40

Multicenter Study Group (1992): Diagnosis of Duchenne and Becker muscular dystrophy by polymerase chain reaction. JAMA 267: 2609-2615

Roberts RG, Cole CG, Hart KA, Bobrow M, Bentley DR (1989): Rapid carrier and prenatal di- 
agnosis of Duchenne and Becker muscular dystrophy. Nucleic Acids Res 17: 811

Sannomiya K (1991): DNA diagnosis of progressive muscular dystrophy by PCR technology. Annual report of research on the genetic, epidermiologic, clinical, and therapeutic aspects of muscular dystrophy supported by the National Center for Neurology and Psychiatry (NCNP) of the Ministry of Health and Welfare, Japan. 65-69

Sugino S, Fujishita S, Kamimura N, Matsumoto T, Wapenaar MC, Deng HX, Shinuya N, Miike T, Niikawa N (1989): Molecular-genetic study of Duchenne and Becker muscular dystrophies: Deletion analyses of 45 Japanese patients and segregation analyses in their families with RFLPs based on the data from normal Japanese females. Am J Med Genet 34: 555-561 